\title{
An Application of Analytic Hierarchy Process (AHP) and Sensitivity Analysis for Maintenance Policy Selection
}

\author{
Damjan Maletič ${ }^{1}$, Matjaž Maletič ${ }^{1}$, Viktor Lovrenčić ${ }^{2}$ Basim Al-Najjar ${ }^{3}$, Boštjan Gomišček ${ }^{1}$ \\ ${ }^{1}$ University of Maribor, Faculty of Organizational Sciences, Kidričeva 55a, 400 Kranj, Slovenia, damjan.maletic@fov. \\ uni-mb.si, matjaz.maletic@fov.uni-mb.si, bostjan.gomiscek@fov.uni-mb.si \\ ${ }^{2}$ C\&G d.o.o. Ljubljana, Riharjeva ulica 38, 1000 Ljubljana, Slovenia, viktor.lovrencic@c-g.si \\ ${ }^{3}$ Linnaeus University, School of Engineering, Sweden, basim.al-najjar@Inu.se
}

Purpose: The purpose of this paper is to apply an analytic hierarchy process (AHP) for the evaluation/selection of maintenance policy.

Methodology/Approach: The paper adopts a case study approach of selecting most appropriate maintenance policy in the case of Slovenian paper mill company. Several steps of the AHP method are used in order to structure the decisionmaking process. Five possible alternatives are considered: failure based maintenance, preventive maintenance, total productive maintenance, reliability centered maintenance and total quality maintenance.

Findings: This paper proposes a framework for maintenance policy selection based on the AHP methodology. The framework was applied to select the most appropriate maintenance policy in a paper mill company. The results suggest that total quality maintenance is the most suitable concept for a paper machine. By performing a sensitivity analysis, it was revealed that the final outcome remained stable in all cases when the weights of the main criteria were increased for 25 percent.

Originality/value: The paper contributes to the literature by providing a framework for decision-making process regarding the maintenance policy selection. In addition, this paper utilizes an exponentially weighted moving average (EWMA) chart for performing a consistency test. Moreover, a sensitivity analysis also presents an important implication of this study.

Keywords: Analytical hierarchy process, decision-making, maintenance policy

\section{Introduction}

Increased competition has forced companies to improve the quality of their products, to increase efficiency as well as to revise their skills, methods and manufacturing practices, which is considered crucial to gain a good reputation and business success (Sharabi, 2014). Therefore, many companies are seeking ways to gain competitive advantages with respect to cost, service, quality, and on- time deliveries (Luxhoj et al., 1997). Manufacturing companies face a great pressure to reduce their production costs (Wang et al.,
2007). The estimated cost of maintenance ranges between 15 and 40 percent of production costs (Dunn, 1987), or even higher. Bevilacqua and Braglia (2000) reported that maintenance costs can reach up to 70 percent of production costs. Thus, the potential impact of maintenance at the level of operations and logistics is considerable, and therefore the financial implications of maintenance can be substantial (Waeyenbergh and Pintelon, 2002). Given these facts, there is a need to select a proper maintenance policy. Several rationales behind this need are as follows. First, Löfsten (1999) stressed that proper management of maintenance

Received: September $6^{\text {th }}, 2013$; revised: June $6^{\text {th }} 2014$; accepted; July $10^{\text {th }}, 2014$ 
offers many companies significant potential of improving efficiency, productivity and profitability. Second, Al-Najjar (2007) discussed the role of efficient maintenance in the enhancement of the company' internal effectiveness for achieving better competitive advantages. Author indicated that when maintenance contribution in the production profit is more than its cost is considered cost-effective. Moreover, in a study (Ljungberg, 1998) author found that the mean percentage of OEE within the investigated cases was 55 percent. Therefore, industry could increase its performance and production capacity without investing in new machinery if an efficient maintenance policy would be implemented (Al-Najjar and Alsyouf, 2004).

Within recent times, there has been also increased emphasis on the health, safety, security and environment (Parida and Chattopadhyay, 2007). With this respect, companies should produce high quality products at a competitive price in addition to showing concern for the environment and safety (Alsyouf, 2004). The extension of this claim is that companies may need to consider different aspect such as plant functionality, environmental safety and cost effectiveness in maintenance, in order to enhance their competitiveness. Therefore, it is important for decision makers to select a proper maintenance policy, which helps companies to achieve their objectives, and boost competitiveness.

A number of empirical studies that focused on maintenance policy selection have been reported in the literature. Azadivar and Shu (1999) proposed the effective methods of selecting appropriate maintenance strategies for just in time production systems. Okumura and Okino (2003) presented the maintenance selection method based on production loss and maintenance cost. Bevilacqua and Braglia (2000) used an analytical hierarchy process (AHP) for maintenance selection in an oil refinery. In their study four evaluation criteria (damages produced by a failure, applicability of the maintenance policy, added value created by the policy, and the cost of the policy) that influenced the primary goal were used. Many different multiple criteria decision-making (MCDM) methods were also adopted in maintenance strategy selection process. For example, Al-Najjar and Alsyouf (2003) assessed the most popular maintenance strategies using the fuzzy inference theory and fuzzy MCDM evaluation methodology. Authors identify the criteria using past data and technical analysis of processes machines and components. Wang et al. (2007) evaluated maintenance strategies based on the fuzzy AHP method. Authors used safety, cost, added-value and feasibility as main criteria. Bertolini and Bevilacqua (2006) proposed a combined goal programming and AHP for maintenance selection through the use of the classic parameters occurrence, severity and detectability. In a more recent study (Zaim et al., 2012) authors used AHP and ANP decision-making methodologies for the selection of the most appropriate maintenance strategy.

Literature search identified different research works that have dealt with maintenance policy selection. While drawing on prior studies related to the application of the AHP for maintenance policy selection (e.g. Bevilacqua and Braglia, 2000), this paper makes a contribution by utilizing quality control approach for consistency test. Moreover, this paper explores the applicability of this model in the case of industrial scenario. For this purpose a case study in a paper mill is conducted.

The remainder of this paper is structured as follows. Section 2 discusses on the maintenance approaches. Section 3 presents the brief description of the AHP method. Section 4 demonstrates a case study and illustrates the proposed framework. Section 5 concludes this paper with several major conclusions drawn from the research.

\section{Critical reflection: a literature review on maintenance approaches}

Several maintenance approaches, i.e. strategies and concepts, methodology or philosophy have been developed and implemented through the evolution of maintenance.

Failure based maintenance (FBM) prescribes activation of maintenance in the event of failure (Gits, 1994), and no action is taken to detect or to prevent failure (Al-Najjar and Alsyouf, 2003). In a situation where customer demand exceeds supply and profit margins are large, this was a feasible approach. However, today we face global competition, small profit margins, high safety awareness and strict environmental regulations. Therefore, more emphasis is placed on developing maintenance concepts (Arts et al., 1998). Nonetheless, it is always possible that a failure is allowed to occur and then repaired. This depends on the existence of secondary damage, redundancy and the ease to repair. In the case of technical feasibility of FBM for a critical component or a non-critical component, the economic feasibility must be determined (Waeyenbergh and Pintelon, 2002).

The main objective of carrying out preventive maintenance $(\mathrm{PM})$ is to reduce the frequent and sudden sporadic failures by performing repairs, replacement, overhauling, lubrication, cleaning and inspection (Gits, 1992). Traditional preventive maintenance models are using policies such as age replacement and block replacement (Reineke et al., 1999). One of the disadvantages of the PM is that PM is only economical where the standard deviation of the failure population is small (Mann et al., 1995). The other critical aspects considering PM are the lack of decision support systems and insufficient historical data (see Dekker, 1996; Al-Najjar and Alsyouf, 2003).

Condition-based maintenance (CBM) is a maintenance program that recommends maintenance decisions based on the information collected through condition monitoring (Jardine and Banjevic 2006). CBM is considered as a management toolbox required for planning maintenance activities, such as data acquisition, analysis, scheduling and conducting maintenance actions cost-effectively (Al-Najjar, 
2012). Vibration-based maintenance (VBM) is the most common technique under the CBM approach, especially for rotating components. According to Al-Najjar (1997) the implementation of VBM policy provides possibilities for acquiring early indications of changes of machine-state. Nevertheless, Al-Najjar (2012) indicated that there is a need to discuss how to establish and run cost-effective CBM. In his paper he developed the steps required for establishing and running cost-effective CBM exemplified for VBM.

Total quality maintenance (TQMain) is a concept to maintain and improve continuously the technical and economic effectiveness of the production process and its elements, i.e. it is not just a tool to serve or repair failed machines rather than a means to maintain the quality of all the elements involved in the production process (Al-Najjar, 1996). Al-Najjar and Alsyouf (2000) also describe what characterises TQMain and distinguish it from other maintenance concepts (e.g. RCM, TPM). In this context features can be summarized in the following: TQMain advocates the use of a common database, continuous improvement, implementation of CBM such as VBM, and it is based on intensive use of real-time data acquisition and analysis to detect causes behind deviations in product quality and machine condition (Al-Najjar and Alsyouf, 2000).

Reliability centered maintenance (RCM) was originally designed for the aircraft industry (Nowlan and Heap, 1978). There have also been several improvements to the traditional RCM methodology for different applications, e.g. RCM2 (Moubray, 1997). RCM combines several management techniques and tools, such as failure mode and effect analysis and decision trees, in a systematic approach, to support effective and efficient maintenance decision (Backlund and Akersten, 2003). It takes into account system functionality, and not just the equipment itself. Applying RCM helps to increase the asset's lifetime and establish a more efficient and effective maintenance (Pintelon and Parodi, 2008). However, Al-Najjar (1997) indicated that RCM does not fully exploit the use of condition monitoring $(\mathrm{CM})$ techniques, and the progress of damage cannot be followed until just before failure. In addition, Pintelon and Parodi (2008) reported that within RCM available statistical data are insufficient or inaccurate, and that there is a lack of insight in the equipment degradation process (failure mechanisms) and the physical environment (e.g. corrosive or dusty environment) is ignored.

Total productive maintenance (TPM) is an approach to continuously improve the performance as well as efficiency of certain industrial activities, and in the first place of maintenance. To do so, the Overall Equipment Effectiveness (OEE) is used, which is the product of availability, speed and quality performance (Waeyenbergh and Pintelon, 2002). Nakajima (1989), a major contributor of TPM, has defined TPM as an innovative approach to maintenance that optimizes equipment effectiveness, eliminates breakdowns, and promotes autonomous maintenance by operators. According to the Nakajima (1988), the concept of TPM includes five elements: (1) TPM aims to maximize equipment effectiveness, (2) TPM establishes a thorough system of PM for the equipment's entire life cycle, (3) TPM is implemented by various departments in a company, (4) TPM involves every single employee, from top management to workers on the shop floor, (5) TPM is an aggressive strategy focuses on actually improving the function and design of the production equipment. The TPM concept is simple and obvious, but there are some reported shortcomings. First, TPM does not provide clear rules to decide which basic maintenance policy will be used, and second calculation of the OEE is not really a complete analysis. Cost and profits are not taken into account, and therefore it is not a complete measure (Waeyenbergh and Pintelon, 2002). Moreover, TPM also require changing the corporate culture, which is not easily to achieve. For instance, as reflected by the study of Tsang and Chan (2000), organizations that are not ready to change their culture will not be successful in implementing TPM.

\section{Introduction to AHP}

The AHP was developed first by Saaty (1980). AHP is a method for solving complicated and unstructured problems that may have interactions and correlations among different objectives and goals. AHP provides an effective method in order to deal with complex decision-making and can assist in identifying and weighing criteria, analyzing the data collected and advancing the decision-making process. It is designed to solve complex problem into different levels of hierarchy with objective/goal in the top, while the intermediate levels are the criteria and sub-criteria, and the lowest level represents alternatives (Saaty, 1980). The AHP is a theory of measurement through pair-wise comparisons and relies on the judgements of experts to derive priority scales (Saaty, 2008). AHP develops priorities among all the criteria and sub-criteria within each level of the hierarchy. Accordingly, AHP method received considerable attention among decision makers and has demonstrated its applicability in different fields, such as maintenance policy selection. The latter is more deeply illustrated in the introduction section. However, this method can also be utilized in many other fields. For example, in the study (Aslani and Aslani, 2012), the fuzzy AHP was employed to prioritize and select a suitable organizational structure.

\section{A case study}

An empirical case study was utilised aiming to evaluate and select the most appropriate maintenance approach. The case study was conducted at a Slovenian paper mill company. Maintenance is highly crucial for this company, considering the fact that processes are running 24/7. In order to extend 
equipment life, improve equipment availability and maintain equipment in proper condition efficient maintenance is essential. Thus, the main aim is to ensure smooth running of a paper machine, mainly to provide on time delivery at low prices. The objective of this study is therefore, to propose the most appropriate maintenance policy that meets these objectives. In the following section, the AHP with a statistical quality control approach for consistency test is applied to the selection of maintenance policy for a paper machine.

\subsection{An AHP based framework for maintenance policy selection}

The AHP modelling process includes four phases, namely, outlining the problem, structuring the decision hierarchy, pair-wise comparison for each matrix, using the priorities obtained from the comparisons to weigh the priorities in the level immediately below, and continuing this process of

Level 1:

Goal/objective

\section{Maintenance policy \\ evaluation/selection \\ for a paper machine}

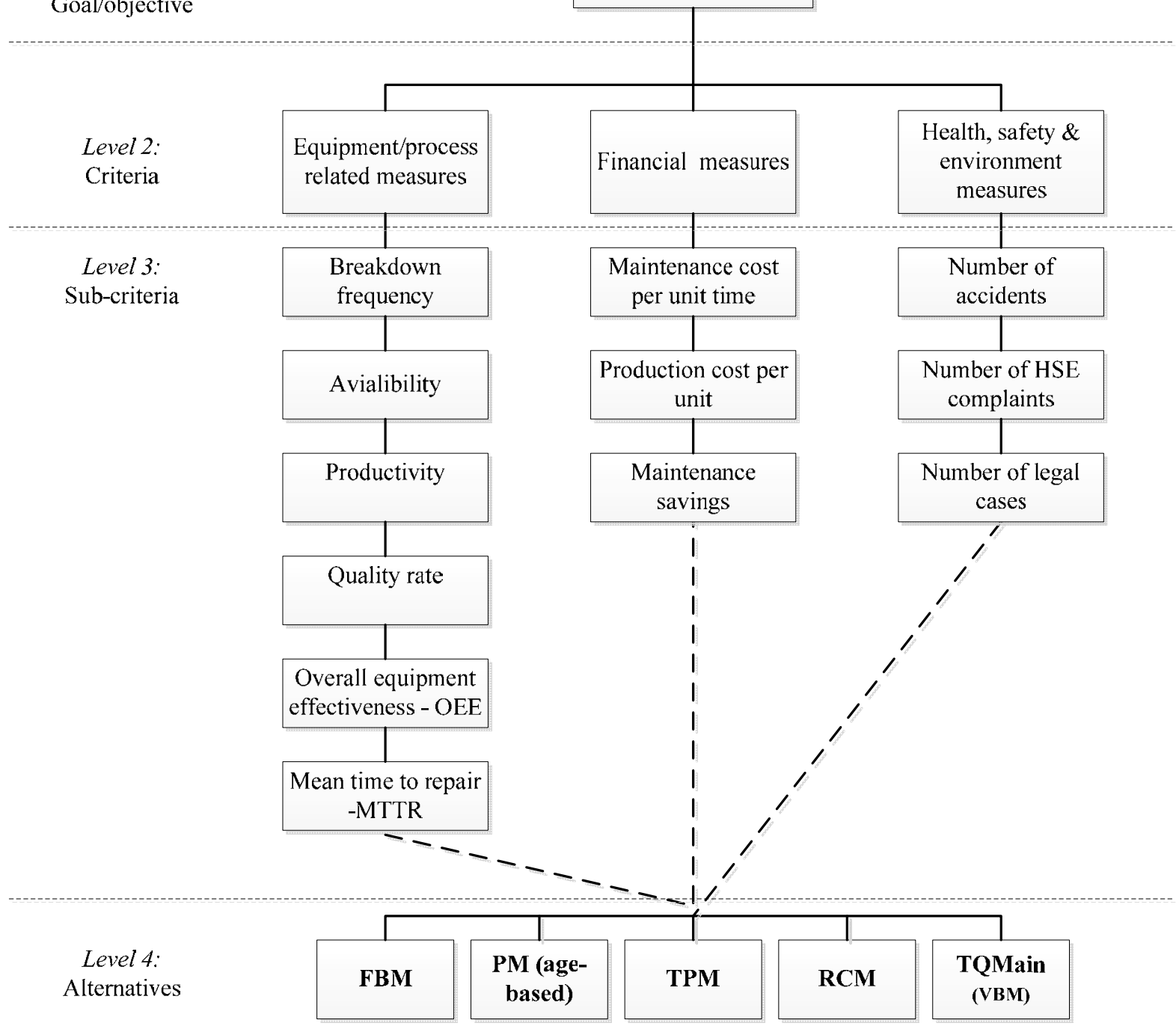

Figure 1: A hierarchy model for maintenance policy evaluation/selection 
weighing and adding until the final priorities of the alternatives are attained (Saaty, 2008). Using these guidelines, an AHP framework was developed for facilitating the study. Therefore, we proposed the following steps:

Step 1: Define the objective or goal

Step 2: Identify criteria and sub-criteria for maintenance policy selection

Step 3: Determine the alternative maintenance approaches

Step 4: Construct a hierarchy framework for analysis

Step 5: Collect empirical information and data

Step 6: Perform pair-wise comparisons for each level of criteria and sub-criteria

Step 7: Perform the consistency test

Step 8: Calculate the global weights of each criteria and sub-criteria

Step 9: Synthesize the results

Step 10: Sensitivity analysis

Step 11: Final ranking of proposed alternatives

\section{Step 1: Define the objective or goal}

The objective of the study is to evaluate and select the most appropriate maintenance approach/policy for a paper machine in the observed company.

\section{Step 2: Identify criteria and sub-criteria for maintenance \\ policy selection}

In this study equipment and process related measures, financial measures and health, safety and environment measures were applied as criteria for the maintenance policy selection. A literature survey was made using the databases such as Emerald, ABI/Inform and ScienceDirect. The search was done in different combinations of keywords such as maintenance performance, maintenance indicators, maintenance costs, maintenance savings and maintenance measurement. Results of the search show different works that have dealt with topics related to these keywords (e.g. Al-Najjar et al., 2004; Muchiri et al., 2011; Parida and Chattopadhyay, 2007). In this regard, various maintenance performance measures were identified from these studies. Finally, a group consisting of three decision makers involved in this case study selected measures for the purpose of this study.

Step 3: Determine the alternative maintenance approaches Different maintenance approaches, i.e. strategies and concepts, methodology or philosophy, were used in this study. These are: FBM, PM, TPM, RCM and TQMain (using VBM).

\section{Step 4: Construct a hierarchy framework for analysis}

The criteria and sub-criteria were structured into a hierarchy descending from the overall objective or goal to the various stages and related sub-criteria in successive levels. The top level of the hierarchy represents the defined objective, while the second level of the hierarchy consists of three main maintenance criteria. These criteria are decomposed into various sub-criteria, as can be seen in Figure 1. Finally, the bottom level of the hierarchy represents the alternative maintenance approaches/policies.

\section{Step 5: Collect empirical information and data}

After building the AHP hierarchy, the next phase is the measurement and data collection, which involves forming a team of evaluators. In this study, a group of 3 evaluators were chosen for evaluating the selected criteria and subcriteria. Two evaluators were chosen from academia having experience in the field of maintenance, and one from industry also experienced in the field of maintenance.

Step 6: Perform pair-wise comparisons for each level of criteria and sub-criteria

Before conducting the pairwise comparison, all members of the group were given the instruction on how to perform the comparison. As mentioned earlier, the pairwise comparison judgement matrices were obtained from three evaluators. Evaluators were requested to compare carefully criteria of each hierarchy level by assigning relative scales in a pairwise fashion with respect to the objective of the presented model. These judgements were then combined using the geometric mean approach at each hierarchy level to obtain the corresponding consensus. A relational scale of real numbers from 1 to 9 used in ranking is presented in Table 1. The purpose of this scale is to determine how many times more important or dominant one element is over another element with respect to the criterion or property with respect to which they are compared (Saaty, 2008).

Table 1: Scale of relative preference for pair-wise comparison

\begin{tabular}{ll}
\hline Scale & Judgement \\
\hline 1 & Equal importance \\
3 & Moderate importance of one over the other \\
5 & Essential or strong importance \\
7 & Very strong or demonstrated importance \\
9 & Extreme or absolute importance \\
& Intermediate values between the two adjacent \\
$2,4,6,8$ & judgements \\
\hline
\end{tabular}

Step 7: Perform the consistency test

This step examines whether the created pairs of criteria are consistent or not (Talib et al., 2011). Usually, the consistency ratio (CR) is used to check whether a criterion can be used for decision-making. Saaty (1980) recommends consistency ratio (CR) should be below 10 percent. On the contrary if $\mathrm{CR}$ is greater than 10 percent, one should examine the possible cause. However, the standard consistency test has been criticized by a number of authors (see for example Lane and Verdini, 1989; Murphy, 1993; Karapetrovic and Rosenbloom, 1999). In this regard, we adopted a quality control approach for the consistency test, 
proposed by Karapetrovic and Rosenbloom (1999). In their study authors suggested that quality control of consistency can be performed using the simple Shewhart Xbar-R chart or exponentially weighted moving average (EWMA) chart. However, we used EWMA chart in order to identify a small shifts in the consistency index (CI). CI is obtained by the following equation: $\mathrm{CI}=\left(\lambda_{\max }-n\right) /(n-1)$, where ' $n$ ' is the number of criteria or sub-criteria of each level and $\lambda_{\text {max }}$ is the largest eigenvector in the matrix. In place of dividing each CI by the "random index", we used an approach to plot the average (considering all decision makers) CI values on EWMA chart (Figure 2). A free software environment for statistical computing and graphics $\mathrm{R}$ was applied using the QCC (an R package for quality control charting and statistical process control) package. We used a default value of smoothing parameter $(\lambda)$, which is set at 0.2 in the aforementioned R package. As can be seen from Figure 2 EWMA values are within control limits. This indicates that decision makers were consistent.

Step 8: Calculate the global weights of each criteria and sub-criteria

The following step includes a calculation of local and global weights. While local weights refer to the preceding hierarchical level, the global weights take into account the highest hierarchical level (Talib et al., 2011). The local and global weights as well as the corresponding ranks are presented in Table 2.

\section{Step 9: Synthesize the results}

In order to obtain final results, all alternatives are multiplied by the global weight of the single decision criteria. The results are summarized in Table 3.

As shown in Table 3, the global priorities are calculated for each of the alternative. The highest value (0.498) correspond to the TQMain, followed by TPM $(0.207)$ and RCM (0.162). As expected the lowest value refers to the FBM.

\section{Step 10: Sensitivity analysis}

Finally, a sensitivity analysis is held to show the effect of altering different parameters of the model on the choice of the maintenance policy selection. First, the current values of the model are presented. Figure 3 demonstrates the current importance of each alternative considering all criteria used in this model. As can be seen from Figure 3 the highest value corresponds to TQMain $(49.8 \%)$. Additionally, Figure 3 also shows the values of the weights of all three main criteria from level 2 (C1 - Equipment/process related measures, C2 - Financial measures and C3 - Health, safety $\&$ environment measures).

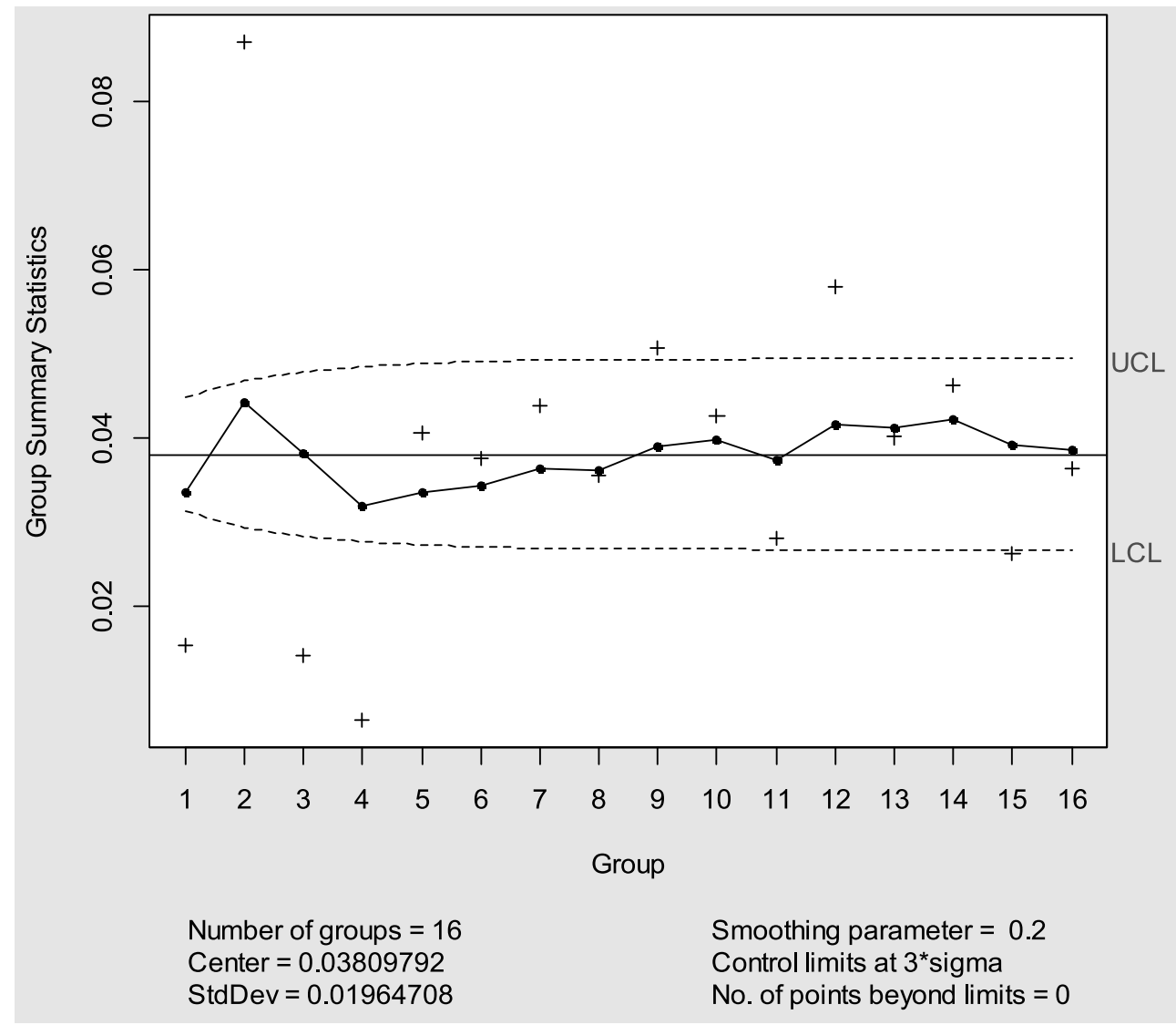

Figure 2: EWMA control chart-average CIs 
Table 2: The local and global weights

Level 2

With respect to maintenance performance measures

Equipment/process related measures

Financial measures

Health, safety \& environment measures

\section{Hierarchy level Criteria}

\begin{tabular}{lccc}
\multicolumn{2}{c}{ Local weights } & \multicolumn{2}{c}{ Global weights } \\
\hline Weights & Ranking & Weights & Ranking \\
\hline
\end{tabular}

$\begin{array}{llll}0.530 & 1 & 0.530 & 1 \\ 0.270 & 2 & 0.270 & 2 \\ 0.199 & 3 & 0.199 & 3\end{array}$

Level 3 With respect to equipment/process related measures

Breakdown frequency

$\begin{array}{llll}0.076 & 5 & 0.040 & 9\end{array}$

Avialibility

$\begin{array}{llll}0.181 & 3 & 0.096 & 5\end{array}$

Productivity

0.183

0.097

0.050

0.224

0.422

0.023

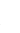

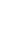

3

Quality rate

Overall equipment effectiveness - OEE

0.043

6

0.127

3

0.034

10

0.243

2

0.066

6

Maintenance savings

0.630

0.170

2

With respect to health, safety \& environment measures

Number of accidents

0.626

Number of HSE complaints

0.233

0.141

Number of legal cases

1

2

6


Table 3: The summarized matrix

\begin{tabular}{|c|c|c|c|c|c|c|c|c|c|c|c|}
\hline & $\begin{array}{l}\text { Criteria } \\
\text { weight }\end{array}$ & FBM & $\begin{array}{l}\text { Weight } \\
\mathrm{x} \text { FBM }\end{array}$ & $\mathrm{PM}$ & $\begin{array}{l}\text { Weight } \\
\text { x PM }\end{array}$ & ТРM & $\begin{array}{l}\text { Weight } \\
\mathrm{x} \text { TPM }\end{array}$ & $\mathrm{RCM}$ & $\begin{array}{l}\text { Weight } \\
\mathrm{x} \text { RCM }\end{array}$ & $\begin{array}{l}\text { TQMain } \\
\text { (VBM) }\end{array}$ & $\begin{array}{l}\text { Weight } x \\
\text { TQMain } \\
\text { (VBM) }\end{array}$ \\
\hline \multicolumn{12}{|l|}{$\begin{array}{l}\text { With respect to equip- } \\
\text { ment/process related } \\
\text { measures }\end{array}$} \\
\hline Breakdown frequency & 0.040 & 0.045 & 0.002 & 0.084 & 0.003 & 0.192 & 0.008 & 0.213 & 0.009 & 0.467 & 0.019 \\
\hline Avialibility & 0.096 & 0.041 & 0.004 & 0.103 & 0.010 & 0.215 & 0.021 & 0.136 & 0.013 & 0.505 & 0.048 \\
\hline Productivity & 0.097 & 0.036 & 0.003 & 0.087 & 0.008 & 0.198 & 0.019 & 0.191 & 0.019 & 0.487 & 0.047 \\
\hline Quality rate & 0.050 & 0.039 & 0.002 & 0.080 & 0.004 & 0.156 & 0.008 & 0.214 & 0.011 & 0.511 & 0.026 \\
\hline $\begin{array}{l}\text { Overall equipment effec- } \\
\text { tiveness - OEE }\end{array}$ & 0.224 & 0.034 & 0.008 & 0.095 & 0.021 & 0.219 & 0.049 & 0.148 & 0.033 & 0.504 & 0.113 \\
\hline $\begin{array}{l}\text { Mean time to repair } \\
\text {-MTTR }\end{array}$ & 0.023 & 0.046 & 0.001 & 0.103 & 0.002 & 0.243 & 0.006 & 0.112 & 0.003 & 0.496 & 0.011 \\
\hline \multicolumn{12}{|l|}{$\begin{array}{l}\text { With respect to financial } \\
\text { measures }\end{array}$} \\
\hline $\begin{array}{l}\text { Maintenance cost per } \\
\text { unit time }\end{array}$ & 0.034 & 0.040 & 0.001 & 0.105 & 0.004 & 0.157 & 0.005 & 0.223 & 0.008 & 0.475 & 0.016 \\
\hline Production cost per unit & 0.066 & 0.031 & 0.002 & 0.091 & 0.006 & 0.221 & 0.014 & 0.172 & 0.011 & 0.485 & 0.032 \\
\hline Maintenance savings & 0.170 & 0.043 & 0.007 & 0.098 & 0.017 & 0.235 & 0.040 & 0.108 & 0.018 & 0.516 & 0.088 \\
\hline \multicolumn{12}{|l|}{$\begin{array}{l}\text { With respect to health, } \\
\text { safety \& environment } \\
\text { measures }\end{array}$} \\
\hline Number of accidents & 0.125 & 0.042 & 0.005 & 0.082 & 0.010 & 0.177 & 0.022 & 0.185 & 0.023 & 0.513 & 0.064 \\
\hline $\begin{array}{l}\text { Number of HSE com- } \\
\text { plaints }\end{array}$ & 0.046 & 0.040 & 0.002 & 0.097 & 0.004 & 0.207 & 0.010 & 0.207 & 0.010 & 0.450 & 0.021 \\
\hline Number of legal cases & 0.028 & 0.043 & 0.001 & 0.086 & 0.002 & 0.201 & 0.006 & 0.201 & 0.006 & 0.469 & 0.013 \\
\hline$\Sigma$ & & & 0.039 & & 0.093 & & 0.207 & & 0.162 & & 0.498 \\
\hline
\end{tabular}

Furthermore, a series of sensitivity analysis were conducted to investigate the impact of changing the priority of the criteria on the alternatives' ranking. Dynamic sensitivity of Expert

Choice was performed to analyse the change in outcome caused by a change in each of the main criterion. The aim of sensitivity analysis is to explore how these changes affect the priorities of the selected alternatives. In the following three scenarios are presented. First, the criterion "equipment/process related measures" was increased for approximately 25 percent (from 53 to 66.2). The results are presented in Figure 4. This figure consists of two parts. The results presented on the left side of the Figure 4 are criteria and their corresponding weights, while the right side of the figure illustrates the ranking of the alternative as expressed by importance (in percentage). The results of the sensitivity analysis revealed that change in the first criterion has no significant influence on the importance of the alternatives. Therefore, one can see that the overall rank of the final outcome remained unchanged in comparison to ranking presented in Table 3.

Second, the criterion "financial measures" was increased for approximately 25 percent (from 27 to 33.8 ) (Figure 5). Consistently with previous findings, the change in this criterion also appears to have no substantial impact on the outcome. As shown in Figure 5 TQMain remains the best alternative.

Finally, the last criterion was also increased for 25 percent (from 19.9 to 25.1), and the model was tested for the change of the outcome. The results show (Figure 6) that the criterion "health, safety and environment measures" has no major impact on the final outcome as well.

Overall, the results of the sensitivity analysis showed that the ranks of the alternatives remained stable in all cases. Additionally, we performed sensitivity analysis in which main criteria were changed down by 10 percent. The results showed that the model is stable also when weights are decreased. This indicates that the proposed model is 

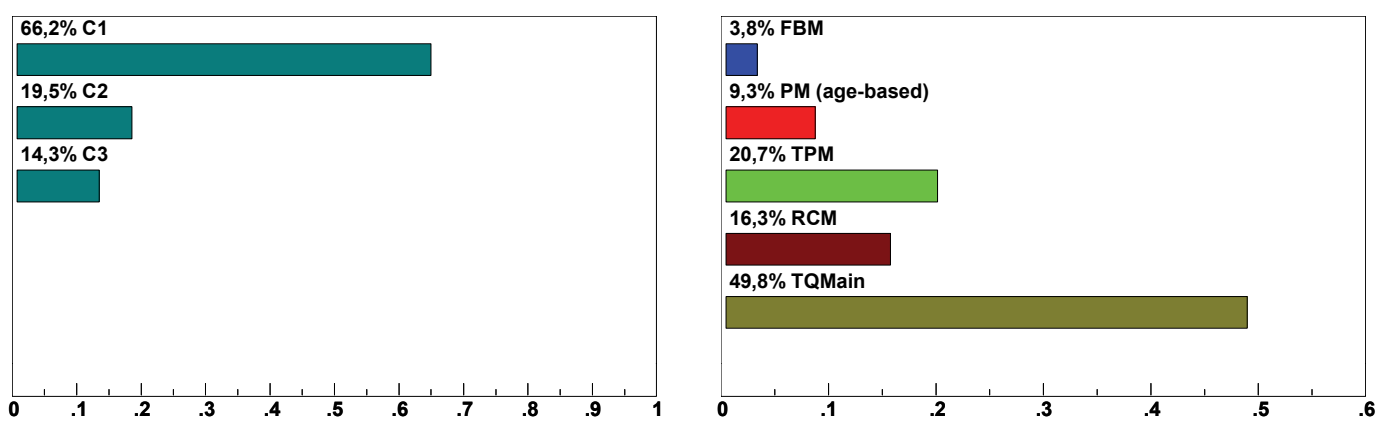

Figure 4: Scenario 1
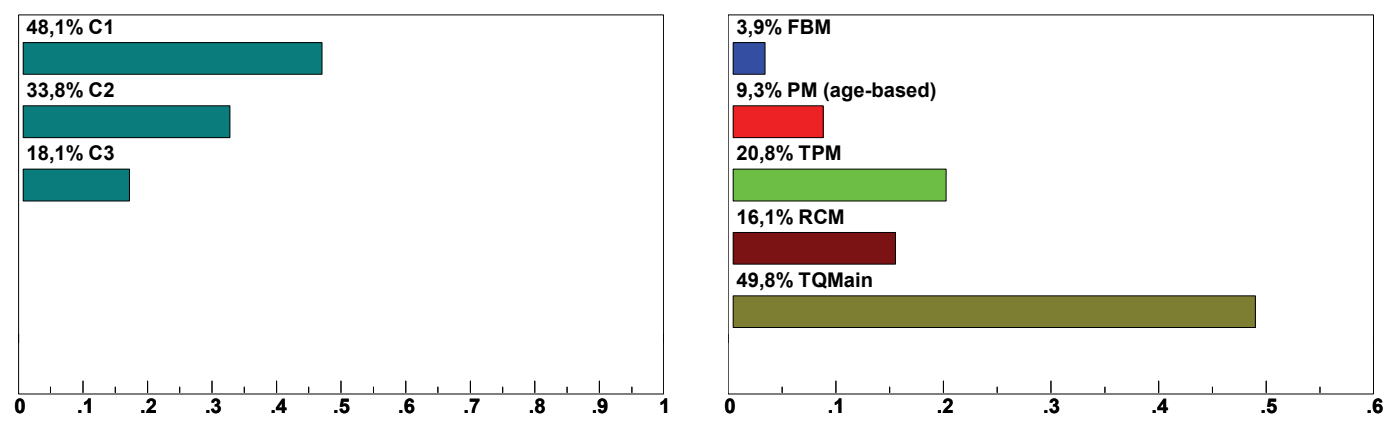

Figure 5: Scenario 2
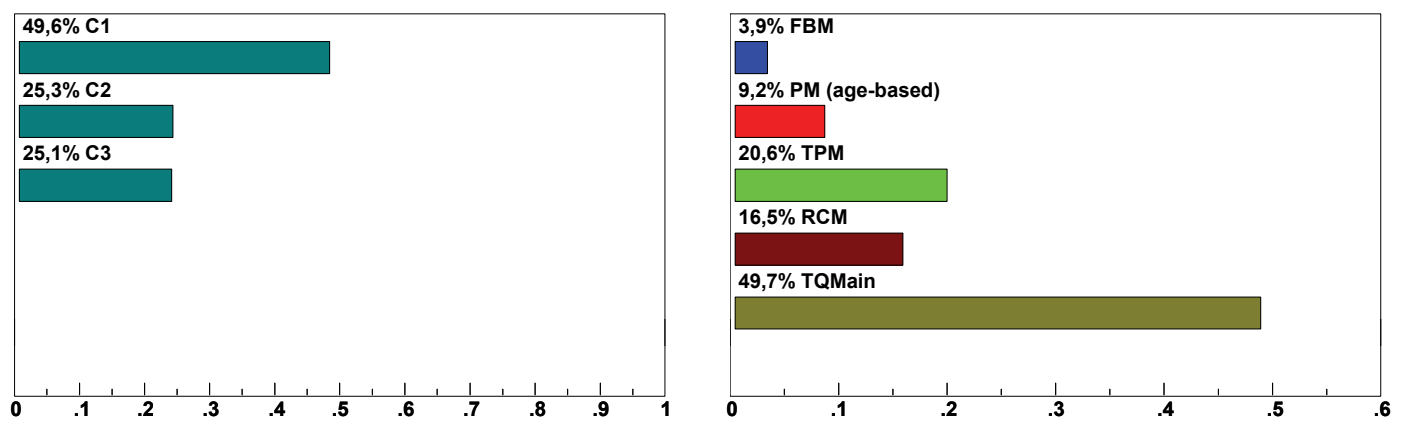

Figure 6: Scenario 3

stable and robust, and thus appropriate for decision-making process.

Step 11: Final ranking of proposed alternatives

Taking account the results of the $9^{\text {th }}$ step and the results of the sensitivity analysis, one can determine the final solution of the AHP method. Therefore, with respect to the main objective of the proposed model, TQMain was selected as the most appropriate maintenance concept (Table 4).
Table 4: Final results of the AHP method

\begin{tabular}{lcc}
\hline Approach & Importance & Rank \\
TQMain & 0.498 & 1 \\
TPM & 0.207 & 2 \\
RCM & 0.162 & 3 \\
PM & 0.093 & 4 \\
FBM & 0.039 & 5 \\
\hline
\end{tabular}




\section{Discussion and conclusion}

In this paper an AHP method was proposed to evaluate/ select the most appropriate maintenance policy from the perspective of a paper mill company. By using the suggested framework the most appropriate maintenance policy can be selected. In this regard, the case study shows that the proposed AHP method is applicable as an evaluation technique, and the proposed framework certainly eases the decision maker's mission of choosing the most efficient maintenance policy. In addition, consistently with an approach used by Karapetrovic and Rosenbloom (1999) our study advocates that a consistency check should be tested in order to verify whether a decision maker has made a mistake in entering the pairwise comparison data rather than whether the decision maker has made random choices. For this purpose EWMA chart is proposed for identifying out-of-control situations which may be caused due to mistakes of a decision maker.

Different management practices can be adopted by manufacturing companies in an effort to improve organizational performance by continuously implementing small changes to the processes (Jaca et al., 2014; Jaca et al., 2012). Selecting a suitable maintenance policy is definitely one of the essential decision-making tasks in improving the cost-effectiveness of the production systems (Al-Najjar and Alsyouf, 2003; Zaim et al. 2012). Recent studies (e.g. Al-Najjar and Alsyouf, 2004) indicate that appropriate maintenance can prolong the life of an asset and prevent costly breakdowns that may result in lost production. Further, the growing importance of maintenance regarding improving company's profitability and competitiveness (e.g. Al-Najjar, 2007; Maletič et al., 2014), strengthens the need for selecting a proper maintenance policy (Bevilacqua and Braglia, 2000). Therefore, using the proposed AHP framework, the criteria for maintenance policy selection can be clearly identified and the problem can be structured systematically. More importantly, it can effectively support the decision makers in the process of selecting the most appropriate maintenance policy.

Three main criteria for the maintenance policy selection were used in this study, as follows: equipment and process related measures, financial measures and health, safety and environment measures. Furthermore, the following sub-criteria are considered to be the most important: OEE, maintenance savings, number of accidents, productivity and availability. The latter can be explained in the context of a production process which is operating 24/7. Seen in this context, used criteria play an important role, especially from the perspective of achieving production goals. Based on the selected criteria as well as on the decision makers' evaluations, the TQMain was selected as the most appropriate maintenance concept. Among others, the TQMain is focused on maintaining and improving continuously the technical and economic effectiveness of the process elements
(Al-Najjar, 1996), which were indeed important criteria in our study.

To ensure that final solution is stable and robust, we additionally applied sensitivity analysis. With Expert Choice software, AHP enables sensitivity analysis of results which is very important in practical decision-making (Bayazit, 2005).

To sum up, the proposed framework appears to enable the structured and systematic way of selecting the most appropriate maintenance policy. By upgrading the traditional AHP method with a EWMA chart for consistency test, our proposed framework for maintenance policy selection represents a valuable tool for decision makers in the field of maintenance. However, we acknowledge the limitations of using the traditional AHP method. This method is often criticized because of its inability to adequately handle the uncertainty and imprecision associated with the mapping of the decision makers' perception to a crisp number (Wang, 2007). Nonetheless, Karapetrovic and Rosenbloom (1999) suggested that quality control approach can be used with any of the variations of AHP. Future studies could therefore consider different versions of AHP for maintenance policy selection in combination with quality control approach.

\section{References}

Al-Najjar, B. (1996). Total quality maintenance. An approach for continuous reduction in costs of quality products. Journal of Quality in Maintenance Engineering, 2(3), 4-20, http://dx.doi. org/10.1108/13552519610130413

Al-Najjar, B. (1997). Condition-based maintenance: Selection and improvement of a cost-effective vibration-based policy in rolling element bearings. Doctoral thesis, ISSN 0280-722X, ISRN LUTMDN/TMIO-1006-SE, ISBN 91-628-2545-X, Lund University, Inst. of Industrial Engineering, Sweden.

Al-Najjar, B. (2007). The lack of maintenance and not maintenance which costs: A model to describe and quantify the impact of vibration-based maintenance on company's business. International Journal of Production Economics, 107(1), 260-273, http://dx.doi.org/10.1016/j.ijpe.2006.09.005

Al-Najjar, B. (2012). On establishing cost-effective condition-based maintenance: Exemplified for vibration-based maintenance in case companies. Journal of Quality in Maintenance Engineering, 18(4), 401 - 416, http://dx.doi. org/10.1108/13552511211281561

Al-Najjar, B., \& Alsyouf, I. (2000). Improving effectiveness of manufacturing systems using total quality maintenance. Integrated Manufacturing Systems, 11(4), 267-76, http:// dx.doi.org/10.1108/09576060010326393

Al-Najjar, B., \& Alsyouf, I. (2003). Selecting the most efficient maintenance approach using fuzzy multiple criteria decision making. Journal of Production Economics, 83(3), 81-96, http://dx.doi.org/10.1016/S0925-5273(02)00380-8

Al-Najjar, B., \& Alsyouf, I. (2004). Enhancing a company's profitability and competitiveness using integrated vibration-based maintenance: a case study. European Journal of Operational Research, 157(3), 643-657, http://dx.doi. org/10.1016/S0377-2217(03)00258-3 
Alsyouf, I. (2004). Cost effective maintenance for competitive advantages. Ph.D. dissertation (Terotechnology), School of Industrial Engineering, Vaxjo University Press, Acta Wexionensia, Vaxjo.

Arts, R.H.P.M., Knapp, G.M.J., \& Lawrence, M. (1998). Some aspects of measuring maintenance performance in the process industry. Journal of Quality in Maintenance Engineering, 4(1), 6-11, http://dx.doi.org/10.1108/13552519810201520

Aslani, A., \& Aslani, F. (2012). Application of Fuzzy AHP Approach to Selection of Organizational Structure with Consideration to Contextual Dimensions. Organizacija, 45(5), 246 - 254, http://dx.doi.org/10.2478/v10051-012-0025-1

Azadivar, F., \& Shu, V. (1999). Maintenance policy selection for JIT production systems. International Journal of Production Research, 37(16), 3725-3738, http://dx.doi. org/10.1080/002075499190013

Backlund, F., \& Akersten, P.A. (2003). RCM introduction: process and requirements management aspects. Journal of Quality in Maintenance Engineering, 9(3), 250 - 264, http://dx.doi. org/10.1108/13552510310493701

Bayazit, O. (2005). Use of AHP in decision-making for flexible manufacturing systems. Journal of Manufacturing Technology Management, 16(7), 808-819, http://dx.doi. org/10.1108/17410380510626204

Bevilacqua, M., \& Braglia, M. (2000) The analytic hierarchy process applied to maintenance strategy selection. Reliability Engineering and System Safety, 70(1), 71-83, http://dx.doi. org/10.1016/S0951-8320(00)00047-8

Bertolini, M., \& Bevilacqua, M. (2006). A combined goal programming-AHP approach to maintenance selection problem. Reliability Engineering and System Safety, 91(7), 839-848, http://dx.doi.org/10.1016/j.ress.2005.08.006

Dekker, R. (1996). Applications of maintenance optimization models: a review and analysis. Reliability Engineering and System Safety, 51(3), 229-240, http://dx.doi.org/10.1016/09518320(95)00076-3

Dunn, R. (1987). Advanced maintenance technologies. Plant Engineering, 40(12), 80-2.

Gits, C.W. (1992). Design of maintenance concepts. International Journal of Production Economics, 24(3), 217-26, http:// dx.doi.org/10.1016/0925-5273(92)90133-R

Gits, C.W. (1994). Structuring maintenance control systems. InternationalJournalofOperations \& Production Management, 14(7), 5-17, http://dx.doi.org/10.1108/01443579410062121

Jaca, C., Viles, E., Paipa-Galeano, L., \& Santos, J. (2014). Learning $5 \mathrm{~S}$ principles from Japanese best practitioners: case studies of five manufacturing companies. International Journal of Production Research, http://dx.doi.org/10.1080/0 0207543.2013.878481

Jaca, C., Viles, E., Mateo, R., \& Santos, J. (2012). Components of sustainable improvement systems: theory and practice. The TQM Journal, 24(2), 142-154, http://dx.doi. org/10.1108/17542731211215080

Jardine, A.K.S., Lin, D., \& Banjevic, D. (2006). A review on machinery diagnostics and prognostics implementing condition-based maintenance. Mechanical Systems and Signal Processing, 20(7), 1483-510, http://dx.doi.org/10.1016/j. ymssp.2005.09.012

Karapetrovic, S,. \& Rosenbloom, E.S. (1999). A quality control approach to consistency paradoxes in AHP. European Journal of Operational Research, 119(3), 704-718, http://dx.doi. org/10.1016/S0377-2217(98)00334-8

Lane, E.F., \& Verdini, W.A. (1989). A consistency test for AHP decision makers. Decision Sciences, 20(3), 575-590, http:// dx.doi.org/10.1111/j.1540-5915.1989.tb01568.x

Ljungberg, O. (1998). Measurement of overall equipment effectiveness as a basis for TPM activities. International Journal of Operations and Production Management, 18(5), 495-507, http://dx.doi.org/10.1108/01443579810206334

Luxhoj, J., Riis, J., \& Thorsteinsson, U. (1997). Trends and perspectives in industrial maintenance management. Journal of Manufacturing Systems, 16(6), 437-53, http://dx.doi. org/10.1016/S0278-6125(97)81701-3

Löfsten, H. (1999). Management of industrial maintenanceeconomic evaluation of maintenance policies. International Journal of Operations \&Production Management, 19(7), 716-737, http://dx.doi.org/10.1108/01443579910271683

Maletič, D., Maletič, M., Al-Najjar, B., \& Gomišček, B. (2014). The role of maintenance in improving company's competitiveness and profitability: A case study in a textile company. Journal of Manufacturing Technology Management, 25(4), 441-456, http://dx.doi.org/10.1108/JMTM-04-2013-0033

Mann, L., Saxena, A., \& Knapp, G. (1995). Statistical-based or condition-based preventive maintenance? Journal of Quality in Maintenance Engineering, 1(1), 46-59, http://dx.doi. org/10.1108/13552519510083156

Moubray, J. (1997). Reliability-centered maintenance, 2nd ed. New York: Industrial Press Inc.

Muchiri, P., Pintelon, L., Gelders, L., \& Martin, H. (2011). Development of maintenance function performance measurement framework and indicators. International Journal of Production Economics, 131(1), 295 - 302, http://dx.doi. org/10.1016/j.ijpe.2010.04.039

Murphy, C.K. (1993). Limits on the analytic hierarchy process from its consistency index. European Journal of Operational Research, 65(1), 138-139, http://dx.doi.org/10.1016/03772217(93)90148-G

Nakajima, S. (1989). TPM Development Program: Implementing Total Productive Maintenance, Cambridge, MA: Productivity Press Inc.

Nakajima, S. (1988). TPM: Introduction to Total Productive Maintenance, Cambridge, MA: Productivity Press Inc.

Nowlan, F.S., \& Heap, H.F. (1978). Reliability Centered Maintenance. San Fransisco: United Airlines Publications.

Okumura, S., \& Okino, N. (2003). A maintenance policy selection method for a critical single-unit item in each workstation composing a FMS with CBM optimization. International Journal of COMADEM, 6(2), 3-9.

Parida, A., \& Chattopadhyay, G. (2007). Development of a multi-criteria hierarchical framework for maintenance performance measurement (MPM). Journal of Quality in Maintenance Engineering, 13(3), 241-258, http://dx.doi. org/10.1108/13552510710780276

Pintelon, L., \& Parodi, A. (2008). Maintenance: an evolutionary perspective. In: Kobbacy, K.A.H., \& Murthy, D.N.P. (Eds), Complex System Maintenance Handbook, London: Springer, pp. 21-48.

Reineke, D., Murdock, W., Pohl, E., \& Rehmert, I. (1999). Improving Availability and Cost Performance for Complex Systems with Preventive Maintenance. Proceedings of the 
Annual Reliability and Maintainability Symposium, pp. 383388.

Saaty, T.L. (1980). The Analytic Hierarchy Process, New York, NY: McGraw-Hill.

Saaty, T.L. (2008). Decision making with the analytic hierarchy process. International Journal of Services Sciences, 1(1), 83-98, http://dx.doi.org/10.1504/IJSSCI.2008.017590

Sharabi, M. (2014). Today's quality is tomorrow's reputation (and the following day's business success). Total Quality Management, 25(3-4), 183 - 197, http://dx.doi.org/10.1080/1 4783363.2013.858877

Talib, F., Rahman, Z., \& Qureshi, M.N. (2011). Prioritising the practices of total quality management: An analytic hierarchy process analysis for the service industries. Total Quality Management \& Business Excellence, 22(12), 1331-1351, http://dx.doi.org/10.1080/14783363.2011.625192

Tsang, A.H.C., \& Chan, P.K., (2000). TPM implementation in China: a case study. International Journal of Quality \& Reliability Management, 17(2), 144 - 157, http://dx.doi. org/10.1108/02656710010304555

Wang, L., Chu, J. and Wu, J. (2007). Selection of optimum maintenance strategies based on a fuzzy analytical hierarchy process. International Journal of Production Economics, 107(1), 15163, http://dx.doi.org/10.1016/j.ijpe.2006.08.005

Waeyenbergh, G., \& Pintelon, L. (2002). A framework for maintenance concept development. International Journal of Production Economics, 77(3), 299-313, http://dx.doi. org/10.1016/S0925-5273(01)00156-6

Zaim, S., Turkyilmaz, A., Acar, M.F., Al-Turki, U., \& Demirel, O.F. (2012). Maintenance strategy selection using AHP and ANP algorithms: a case study. Journal of Quality in Maintenance Engineering, 18(1), 16 - 29, http://dx.doi. org/10.1108/13552511211226166

Damjan Maletič is teaching assistant and researcher at the Faculty of Organizational Sciences, University of Maribor. His research activities are mainly devoted to the fields of maintenance management and quality management. At present, his research is focused on studying the interaction between quality management, production and maintenance performance. He holds a bachelor's degree in Wood Science and Technology (University of Ljubljana) and Organization (University of Maribor). He is currently a PhD student at the University of Maribor, Faculty of Organizational Sciences.

Matjaž Maletič is a teaching assistant at Faculty of Organizational Sciences, University of Maribor. His main research interest concerns the quality management, corporate sustainability, integration of quality management and sustainability as well as the overall organizational performance. He holds a bachelor's degree in Wood Science and Technology (University of Ljubljana) and Organization (University of Maribor). He has defended his $\mathrm{PhD}$ thesis in September 2013 at the University of Maribor, Faculty of Organizational Sciences.

Viktor Lovrenčić graduated at the University of Ljubljana, Faculty of Electrical Engineering, and obtained a Master's degree in Power Supply from the same University. He has more than 25 years of experience in the field of electrical engineering and has worked as a junior researcher and assistant at the Faculty of Electrical Engineering, as design manager at Energoinvest Transformer Company Ljubljana, and as a Commercial and Technical Manager at the same company. Currently he is Technical Manager at C\&G d.o.o. Ljubljana. He has been a consultant working for Slovenian utility companies and industry since 2006. He was a member of JWG 27 CIGRE "Live Work A Management Perspective". He is a pioneer and holder of LW activities in Slovenia. He is a member of CIGRE Paris, Slovenian and Croatian CIGRE and CIRED, a member of LWA Technical and Scientific committee and is fluent in Slovenian, Croatian and English languages.

Basim Al-Najjar is Professor of Terotechnology and Chair of Centre for Cost-Effective IndustrialAsset Management, Department of Terotechnology, School of Engineering, Linnaeus University. $\mathrm{He}$ is also CEO of E-maintenance Sweden $\mathrm{AB}$. He obtained his $\mathrm{PhD}$ in production management, Lund University, Sweden. His main research area is Terotechnology. He has many years of experience of teaching and research, mainly in industrial asset management, cost-effectiveness, CBM, problem shooting using vibration spectral analysis, maintenance modelling and optimisation.

Boštjan Gomišček is associate professor at the University of Maribor, Faculty of Organizational Sciences, Slovenia. As head of the Laboratory for Quality Management he is predominantly engaged in the following research fields: quality management, maintenance management and environmental protection. 